\title{
Comparison of penicillin, tetracycline, and doxycycline in the treatment of uncomplicated gonorrhoea in men
}

\author{
H. BAYTCH \\ Medical Officer, Government Clinic, Melbourne \\ AND D. W. RANKIN \\ Chief Health Education Officer, Department of Health, Victoria, Australia
}

In September, 1969, a clinical trial was begun at the State Department of Health's Venereal Disease Clinic, Melbourne, with the aim of testing the efficacy of the two antibiotics, 'Mysteclin V' and 'Vibramycin' (doxycycline), as compared with procaine penicillin and with each other in the treatment of acute uncomplicated gonorrhoea in men.

\section{Methods}

The three drugs in the trial were used in the following dosages:

Procaine penicillin Intramuscular injection of 2 million units on each of three consecutive days.

Mysteclin ' $V$ ' Single dose of six capsules, each containing tetracycline $250 \mathrm{mg}$ and nystatin $250,000 \mathrm{u}$, taken under the supervision of the Clinic staff.

Vibramycin Single oral dose of three capsules, each containing doxycycline $100 \mathrm{mg}$., taken under supervision.

The therapy was allocated in a randomized manner; each patient was given a serial number from 1 to 150 and assigned to one of the three treatment categories by the use of random sampling numbers according to the method described by Hill (1966).

Fifty patients were allotted in this fashion to each of the three treatment subgroups.

It was not considered ethical to adopt a double-blind trial because, if untoward clinical side-effects occurred the clinician in charge should know immediately what treatment had been given to the patient without consulting the statistical adviser.

However, the patient did not know the name of the drug given and the final assessment was a microscopic one, based on the presence or absence of gonococci in a urethral smear; if no urethral discharge was present this was a basic clinical assessment, not liable to personal bias on the part of the clinician. The urethral smear was examined by an experienced laboratory technician who did not know the nature of the treatment and his findings were confirmed by the clinician.

Each patient was assessed for inclusion in the trial by

Received for publication July 9, 1971 the clinician in charge according to the following criteria:

(1) The patients were males with acute uncomplicated gonococcal urethritis;

(2) Diagnosis was made on the findings of Gram-negative intracellular diplococci in the urethral smear;

(3) The patients admitted to the trial had had exposure within the previous 8 days and a discharge which had been present for not more than 5 days.

Any history of drug sensitivity precluded the patient from admission to the trial and no patient was admitted unless he was suitable for treatment by each of the three drugs used.

Once the patient was selected for inclusion in the trial, the clinician selected a sealed envelope serially numbered, containing instructions as to which of the randomly selected treatments was to be employed.

The original treatment decided upon was adhered to throughout the trial. If for any reason it was decided to discontinue one drug and substitute another during the course of the trial, that patient was still recorded as having had the first drug, but the result of his treatment was recorded as unknown when the appropriate assessment was being made.

\section{Assessment}

The clinician in charge assessed all patients:

(i) 24 hours after the cessation of treatment, for the immediate result;

(ii) More than 24 hours and up to 3 weeks after the cessation of treatment, for relapse.

Patients who were considered to be re-infected after the 24-hour assessment were still included in the trial from the point of view of the 24-hour assessment, but from the point of view of a later assessment the result was recorded as unknown.

All patients were questioned as to the possibility of having received additional antibiotics from other sources during treatment, e.g. for intercurrent infection. This was denied in all cases.

The following criteria were employed in the assessment:

GOOD (a) No gonococci detected in urethral smear;

(b) No urethral discharge.

POOR Gonococci detected in urethral smear. Extracellular diplococci were detected in three cases, and these were included in this category. The essential 
criterion was the presence or absence of gonococci in the urethral smear at the appropriate time of assessment.

As will be seen from the dosage schedules and times of assessment, patients could be admitted to the trial only on certain days of the week, as the clinic is open only on Monday to Friday. For this reason and because of the strictness of criteria for admission to the trial, the trial lasted from September, 1969, to December, 1970.

Seamen and transport drivers were excluded from the trial, as the transient nature of their stay in Melbourne rendered follow-up difficult.

\section{Findings}

(1) COMPARABILITY OF GROUPS IN RESPECT OF AGE

(Table I)

(a) Whole group (150) Mean age 24 years, standard deviation $\pm 6 \cdot 7$.

(b) Penicillin-treated group (50) Mean age 26.2 years, standard deviation $\pm 7 \cdot 7$.

(c) Mysteclin ' $V$ '-treated group (50) Mean age 24 years, standard deviation $\pm 5 \cdot 8$.

(d) Vibramycin-treated group (50) Mean age 24.5 years, standard deviation \pm 6 .

The groups were therefore considered comparable in respect of age.

(2) 24-HOUR ASSESSMENT (Table II)

(a) Penicillin v. Mysteclin ' $V$ '

Of the fifty penicillin-treated patients, 43 were assessed 24 hours after cessation of treatment; six had defaulted and one had to be excluded after admission to the trial, for other clinical reasons.

Of the 43 patients who received penicillin 37 (86 per cent.), and of fifty patients who received Mysteclin ' $V$ ' 25 (50 per cent.), were classified as having a 'good' result.

Applying the $\chi^{2}$ test of significance (using 'Yates' correction for small numbers), it was found that the difference between these results was highly significant $\left(\chi^{2}=11.94 ; P<0.01\right)$.

(b) Penicillin v. Vibramycin

Of the fifty patients who received Vibramycin, 49 were assessed at 24 hours, one having defaulted. Of these 49 patients, $25(51.2$ per cent.) were classified as showing a 'good' result, as compared with 86 per cent. of the penicillin-treated patients (as above).

The difference between the results was highly significant $\left(\chi^{2}=11 \cdot 24 ; P<0 \cdot 01\right)$.

(c) Mysteclin ' $V$ ' v. Vibramycin

Fifty per cent. of the Mysteclin ' $V$ '-treated patients and 51.2 per cent. of the Vibramycin-treated patients (as above) were classified as having had a 'good' result.

This slight difference between the two treatments most likely occurred by chance $\left(\chi^{2}=0.01 ; P>0.9\right)$.

TABLE I Age distribution of male patients admitted to clinical trial

\begin{tabular}{|c|c|c|c|c|}
\hline \multirow{2}{*}{ Age group (yrs) } & \multicolumn{4}{|l|}{ No. of patients } \\
\hline & (a) Whole trial & (b) Penicillin & (c) Mysteclin ' $V$ ' & (d) Vibramycin \\
\hline $\begin{array}{l}15-19 \\
20-24 \\
25-29 \\
30-34 \\
35-39 \\
40-44 \\
45-49 \\
50-54 \\
55+ \\
\text { No information }\end{array}$ & $\begin{array}{r}26 \\
69 \\
27 \\
19 \\
4 \\
2 \\
1 \\
0 \\
1 \\
1\end{array}$ & $\begin{array}{r}6 \\
22 \\
11 \\
8 \\
0 \\
1 \\
1 \\
0 \\
1 \\
0\end{array}$ & $\begin{array}{r}12 \\
21 \\
9 \\
6 \\
2 \\
0 \\
0 \\
0 \\
0 \\
0\end{array}$ & $\begin{array}{r}8 \\
26 \\
7 \\
5 \\
2 \\
1 \\
0 \\
0 \\
0 \\
1\end{array}$ \\
\hline Total patients & 150 & 50 & 50 & 50 \\
\hline Mean age (yrs) & $24 \cdot 9$ & $26 \cdot 2$ & $24 \cdot 0$ & $24 \cdot 5$ \\
\hline Standard deviation & \pm 6.7 & $\pm 7 \cdot 7$ & $\pm 5 \cdot 8$ & \pm 6.0 \\
\hline
\end{tabular}

TABLE II Results of 24-hour assessment

\begin{tabular}{|c|c|c|c|c|c|c|c|c|c|}
\hline \multirow{2}{*}{ Result } & \multicolumn{3}{|c|}{ (a) Penicillin v. Mysteclin ' $V$ ' } & \multicolumn{3}{|c|}{ (b) Penicillin v. 'Vibramycin' } & \multicolumn{3}{|c|}{ (c) 'Vibramycin' v. Mysteclin ' $V$ ' } \\
\hline & Penicillin & Mysteclin ' $V$ ' & Total & Penicillin & Vibramycin & Total & Vibramycin & Mysteclin ' $V$ ' & Total \\
\hline $\begin{array}{l}\text { Good } \\
\text { Poor }\end{array}$ & $\begin{array}{r}37 \\
6\end{array}$ & $\begin{array}{l}25 \\
25\end{array}$ & $\begin{array}{l}62 \\
31\end{array}$ & $\begin{array}{r}37 \\
6\end{array}$ & $\begin{array}{l}25 \\
24\end{array}$ & $\begin{array}{l}62 \\
30\end{array}$ & $\begin{array}{l}25 \\
24\end{array}$ & $\begin{array}{l}25 \\
25\end{array}$ & $\begin{array}{l}50 \\
49\end{array}$ \\
\hline Total & $43 \star$ & 50 & 93 & 43* & $49+$ & 92 & $49 \dagger$ & 50 & 99 \\
\hline
\end{tabular}

*' not assessed (6 defaulted; 1 excluded for other clinical reasons)

t. nut assessed (defaulted)

(a) $\chi^{2}=11.94 ; \mathrm{P}<0.01$

(b) $\chi^{2}=11.24 ; P<0.01$

(c) $\dot{\chi}^{2}=0.01 ; P>0.9$ 
(3) RELAPSE (i.e. gonococci present in urethral smear after the 24-hour assessment but within 3 weeks of cessation of treatment, in those who were assessed as showing a 'good' result at 24 hours).

The results are inconclusive as a large percentage of patients could not be assessed for various reasons (Table III):

(i) Re-infection;

(ii) Further treatment needed for post-gonococcal urethritis within this period;

(iii) Default.

\section{Conclusions and discussion}

In this trial it was possible to compare the results of treatment with three antibiotics 24 hours after the cessation of treatment. It was not possible to assess cases satisfactorily beyond this time for various reasons, such as re-infection, persistent postgonococcal urethritis, or default.

The high dosage of three daily injections of 2 million units of procaine penicillin was used because the same problem of increasing resistance of $N$. gonorrhoeae to previously curative dosages of penicillin is occurring in Victoria as in almost all countries of the world (Gray, Phillips, and Nicol, 1970; Smithurst, 1970).

Tables II and III show the following definite failure rates with the antibiotics employed:

$\begin{array}{lrl}\text { Penicillin } & 6 / 43 & 14 \text { per cent. } \\ \text { Mysteclin 'V' } & 33 / 50 & 66 \text { per cent. } \\ \text { Vibramycin } & 26 / 49 & 53 \text { per cent. }\end{array}$

It is emphasized that these are minimum failure rates observed at some time during the 3 weeks after cessation of treatment.

The results of this trial confirm that, in nonallergic patients, procaine penicillin is still the drug of choice of the three tested.

Mysteclin ' $V$ ' and Vibramycin given in single doses yielded too low a rate of cure at the 24-hour assessment to merit their use routinely, but it is suggested that they have their place in the treatment of patients allergic to penicillin who may be transients, e.g. transport drivers and seamen, or in those who are likely to default. In this latter category they may have some effect, however slight, in curbing the spread of disease.

In all patients treated the standard routine was adhered to of blood-testing for syphilis on admission and, wherever possible, again at 3 months from the date of the last sexual exposure.

Since the completion of this trial we have extended the criteria of diagnosis of gonorrhoea and of cure, by the use of cultures performed in the Clinic.

The growth medium used is as follows:

Diagnostic sensitivity test agar base 90 per cent.

Saponin-lysed horse blood 10 per cent.

Trimethoprim

$5 \mathrm{mg} . / \mathrm{ml}$.

Colistin sulphate

Vancomycin hydrochloride

$8 \mathrm{mg} . / \mathrm{ml}$.

$3 \mathrm{mg} . / \mathrm{ml}$.

It is possible that some of those cases noted in Table III as having relapsed would have been detected at an earlier date if cultures had been performed.

\section{Summary}

150 men with uncomplicated gonorrhoea were allocated by random selection for treatment with one of the following antibiotic regimes: procaine penicillin 2 m.u. intramuscularly on 3 successive days; tetracycline in a single oral dose of $1.5 \mathrm{~g}$.; Doxycycline in a single oral dose of $300 \mathrm{mg}$.

The immediate cure rates, as judged by the absence of gonococci from urethral smears 24 hours after treatment, were 86,50 , and 51 per cent. respectively. The difference between the results with penicillin and those with the other regimes was highly significant $(P<0.01)$.

Further assessment within 3 weeks was partially vitiated by a high default rate. In common with many countries, Australia has experienced increasing resistance of $N$. gonorrhoeae, and the authors consider that, of the three drugs tested, only penicillin merits routine use.

TABLE III Relapse within 3 weeks in cases assessed as 'good' at 24 hours

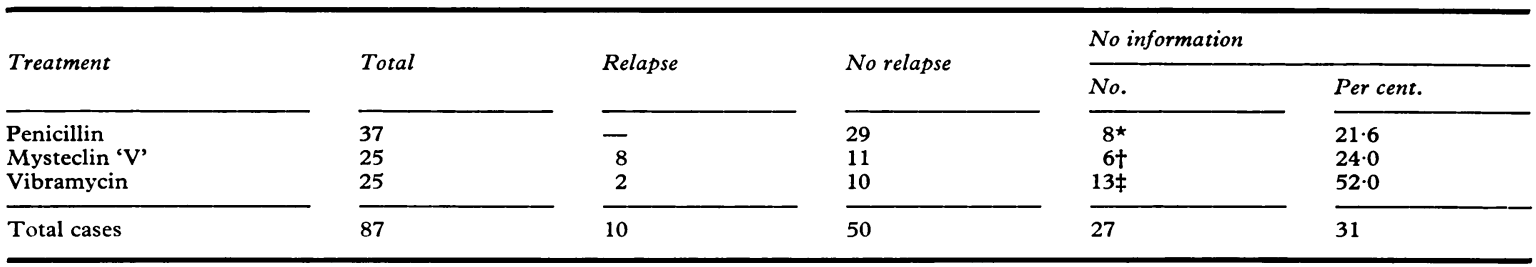

$\star 8$ defaulters

†Another antibiotic had to be given for post-gonococcal urethritis within this period even though no gonococci were evident in urethral smear

at the 24-hour assessment

$\ddagger 3$ defaulters, 2 cases of re-infection, 8 cases required another antibiotic because of post-gonococcal urethritis 
We wish to thank E. R. Squibb \& Sons Pty. Ltd., for supplying Mysteclin ' $V$ ', and Pfizer Pty. Ltd., for supplying Vibramycin for use in this trial.

We also wish to thank Dr. W. J. Stevenson, Chief Health Officer, Department of Health, Victoria, and Dr. K. F. Brennan, Medical Officer-in-charge of Venereal Diseases, for permission to conduct the trial and publish the results, and we gratefully acknowledge the help given by the Central Cancer Registry of the Anti-Cancer Council of Victoria in the preparation and tabulation of data, particularly Mrs. E. Sellton and Mr. D. J. Hill, and the assistance given by Mrs. G. Nam of the Government Health Clinic.

\section{References}

Gray, R. C. F., Phillits, I., and Nicol, C. S. (1970) Brit. F. vener. Dis., 46, 401

Hill, A. B. (1966) 'Principles of Medical Statistics', 8th ed. Lancet, London

SmithuRst, B. A. (1970) Brit. F. vener. Dis., 46, 398
Comparaison de la pénicilline, de la tétracycline et de la doxycycline dans le traitement de la gonococcie masculine non compliquée

\section{SOMMAIRE}

150 hommes atteints de gonococcie non compliquée furent répartis par randomnisation et traités avec une des prescriptions d'antibiotiques suivantes: pénicilline-procaine, 2 m.u. par voie intramusculaire pendant 3 jours consécutifs; tétracycline, $1,5 \mathrm{~g}$. en dose orale unique; doxycycline, $300 \mathrm{mg}$. en dose orale unique.

Les taux de guérison immédiate, jugé sur l'absence de gonocoques dans le prélèvement urétral 24 heures après traitement, furent respectivement de 86,50 et 51 pour cent. La différence des résultats de la pénicilline avec ceux des autres types de traitement fut hautement significative $(\mathrm{P}<0.01)$.

L'évaluation ultérieure dans les trois semaines suivantes fut viciée en partie par le haut taux de défaillance des malades. Comme dans beaucoup de pays, l'Australie connaît une augmentation croissante de la résistance de $N$. gonorrhoeae, et les auteurs considèrent que, parmi les trois médicaments éprouvés, seule la pénicilline convient au traitement de routine. 